\title{
CAPTURA, ESFORÇO E CPUE DO ESPADARTE (Xiphias gladius) DESEMBARCADO EM SANTA CATARINA EM 2000 E 2001
}

\author{
MAYER, F.P. \& H.A. ANDRADE \\ UNIVALI - CTTMar \\ Rua Uruguai, 458 - C.P. 360 - CEP 88302-202 - Itajaí (SC) \\ Email: mayer@cttmar.univali.br - humber@cttmar.univali.br
}

\begin{abstract}
RESUMO
Neste trabalho foram analisados dados referentes ao esforço de pesca e à captura de espadarte (Xiphias gladius), obtidos nos desembarques da frota industrial de espinhel de superfície de Santa Catarina no segundo semestre de 2000 e em 2001. Estes dados foram coletados a partir de um programa iniciado em 2000 , com a intenção de se obter um maior conhecimento sobre a biologia pesqueira desta espécie, e de auxiliar o monitoramento desta pescaria no estado de Santa Catarina, gerando informações úteis para a tomada de decisões de manejo deste recurso no âmbito da ICCAT. Durante o período amostrado, as embarcações concentraram seus esforços geralmente entre $25^{\circ}-40^{\circ} \mathrm{S} / 40^{\circ}-55^{\circ} \mathrm{W}$, porém houveram barcos atuando próximo ao arquipélago de Vitória-Trindade, da elevação do Rio Grande, e das ilhas Malvinas. No geral destaca-se a área delimitada pelas latitudes de $30^{\circ}-35^{\circ} \mathrm{S}$ e longitudes de $45^{\circ}-50^{\circ} \mathrm{W}$, que sempre propiciou capturas relativamente elevadas independente da época do ano. As maiores CPUEs (em kg/dia de pesca com 1000 anzóis) ocorreram normalmente em regiões mais oceânicas (menos exploradas pela frota). No entanto, no $3^{\circ}$ e $4^{\circ}$ trimestres, as áreas costeiras também parecem ser rentáveis. Além do espadarte, as principais espécies capturadas pelos espinheleiros catarinenses foram: a albacora-bandolim (Thunnus obesus), a albacora-branca ( $T$. alalunga), a albacora-lage ( $T$. albacares), e principalmente o cação-azul (Prionace glauca). Comparando-se a contribuição percentual destas espécies, observa-se um predomínio de cação azul em todos os trimestres, especialmente no $1^{\circ}(82 \%)$. O espadarte foi a $2^{\mathrm{a}}$ espécie com maior importância sobre o total em peso desembarcado, aumentando sua contribuição do 1ㅇ (cerca de 12\%) para 0 4을 trimestre (cerca de 22\%). O aumento na contribuição percentual de espadarte ao longo do ano, se deve em parte ao incremento das capturas e CPUEs do próprio espadarte, mas também ao decréscimo substancial da participação do cação azul na captura.
\end{abstract}

Palavras-chave: espadarte, Xiphias gladius, captura, esforço, CPUE, espinhel pelágico.

\section{CATCH, EFFORT AND CPUE OF SWORDFISH (XIPHIAS GLADIUS) LANDED IN SANTA CATARINA STATE IN 2000 AND 2001}

\footnotetext{
ABSTRACT

Fishing effort and catch of swordfish (Xiphias gladius) landed by long-line fleet in Santa Catarina state during 2000 and 2001 were the subject of this study. These data was derived from a sampling program implemented in 2000 , aiming the collection of information on the swordfish fishery and of useful information to support ICCAT management decisions. The fleet concentrated fishing effort in the area between $25^{\circ}-40^{\circ} \mathrm{S} / 40^{\circ}-55^{\circ} \mathrm{W}$. However, there were some boats fishing close to the Vitória-Trindade archipelago, the Rio Grande rise, and the Malvinas Island. In general, high catches were usually observed in the area between $30^{\circ}-35^{\circ} \mathrm{S} / 45^{\circ}-50^{\circ} \mathrm{W}$. Elevated CPUEs (kg/day fishing with 1000 hooks) occurred mostly in oceanic regions (seldom explored by the fleet). However, in the $3^{\text {rd }}$ and $4^{\text {th }}$ quarters, coastal waters also seem to be productive. Beside
} 
swordfish, the main species caught by the long-liners were: bigeye tuna (Thunnus obesus), albacore ( $T$. alalunga), yellowfin tuna ( $T$. albacares), and the blue shark (Prionace glauca). There was a predominance of blue shark in all quarters, especially in $1^{\text {st }}(82 \%)$. Swordfish was the $2^{\text {nd }}$ most important species in the landings, increasing its contribution from the $1^{\text {st }}$ (around $12 \%$ ) to the $4^{\text {th }}$ quarter (around 22\%). This increase in the swordfish landings was caused in part by trends in swordfish increasing catches and CPUEs, but also by the decrease of blue shark catches.

Key-words: swordfish, Xiphias gladius, catch, effort, CPUE, long-line.

\section{INTRODUÇÃO}

No início da pescaria brasileira de espinhel pelágico, o espadarte (meka) (Xiphias gladius) era capturado ocasionalmente como fauna acompanhante por embarcações (principalmente arrendadas), que tinham como espécies-alvo as albacoras ou cações. Os primeiros experimentos de pesca dirigidos ao espadarte foram realizados nos anos de 1980/ 81 , com o uso ainda do espinhel tradicional de nylon multifilamento. (Amorim \& Arfelli, 1984).

No Brasil, em meados de maio de 1994 (em virtude da expansão do mercado), iniciaramse as pescarias que tinham o espadarte como espécie-alvo, acarretando em mudanças no aparelho de pesca dos barcos espinheleiros (Arfelli, 1996). Em particular, devido ao direcionamento da pesca para a captura desta espécie, ocorreu a troca do tradicional nylon multifilamento para o nylon monofilamento. Além disso, o espinhel passou a ser lançado no início da noite, iniciou-se a utilização de atrativos luminosos descartáveis (light stick) e lulas como isca, e o lançamento começou a ser feito para propiciar que o anzol ficasse entre 30 e $200 \mathrm{~m}$ de profundidade. Tais mudanças ocorreram devido ao fato de que o espadarte costuma alimentar-se no período noturno e em águas mais rasas (Arfelli, 1996). Como resultado, os espinheleiros nacionais modificados para a pesca do espadarte, atingiram altas taxas de captura em comparação com as taxas obtidas na pesca utilizando o espinhel tradicional, e consequentemente mais barcos foram recrutados para a pescaria. A frota começou a se desenvolver até mesmo em estados onde nenhuma pesca com espinhel tinha sido relatada, como no estado de Santa Catarina, no sul do Brasil. Cabe mencionar que desde o início da pescaria com espinhel no Brasil, algumas empresas arrendaram embarcações estrangeiras, geralmente com maior porte que os barcos nacionais. Estas embarcações arrendadas possuem maior autonomia, e consequentemente, maior flexibilidade para atuar em áreas distintas, aumentando a possibilidade de maiores rendimentos. Por esse motivo, a composição das capturas da frota arrendada apresenta padrões distintos daquela da frota nacional, além de mostrar grande variação devido ao direcionamento do esforço para diferentes espécies (e.g. albacora-branca, albacora-bandolim) ao longo do desenvolvimento da pescaria (Zavala-Camin \& Tomás, 1990). Estas mudanças na espécie alvo devem estar associadas com mudanças na estratégia dos pescadores e nas áreas de pesca (Meneses de Lima et al, 2000), como resultado das flutuações das demandas por determinadas espécies no mercado internacional. Atualmente, a maior parte dos barcos arrendados atua nos portos de Santos (SP), e da costa nordeste do Brasil (Meneses de Lima et al, 2000).

A frota sediada em Itajaí (SC), com embarcações que utilizam espinhel de monofilamento e capturas direcionadas ao espadarte, iniciou sua operação apenas em 1996. Por se tratar de uma atividade relativamente nova, poucos estudos foram feitos na região sul do Brasil e, portanto, é difícil avaliar a evolução da pescaria (e.g. captura e esforço) ao longo dos anos. 
Por ser uma espécie altamente migratória, o mesmo estoque pode ser explotado por frotas de diferentes países, e portanto, é necessário que o gerenciamento da pescaria de espadarte seja realizado em nível internacional, através de um consenso entre os países que exploram o recurso. A International Commission for the Conservation of Atlantic Tunas (ICCAT) tem o papel de administrar a pescaria desta espécie e dos demais estoques de atuns ( Thunnus sp) e afins (e.g. agulhão-vela). Dados são enviados à ICCAT por seus países membros (dentre os quais o Brasil) para que análises sejam feitas e decisões administrativas sejam tomadas.

O objetivo deste trabalho é fazer uma primeira análise de dados referentes à captura e ao esforço de pesca, obtidos nos desembarques da frota industrial de espinhel de superfície de Santa Catarina no $2^{\circ}$ semestre de 2000 e em 2001. Estes dados, que são também fornecidos para a ICCAT, foram coletados a partir de um programa iniciado em 2000, com a intenção de se obter um maior conhecimento sobre a pescaria do espadarte, podendo ser útil no âmbito da ICCAT. Através de índices de vulnerabilidade e/ou abundância (e.g. Captura Por Unidade de Esforço - CPUE) (Gulland, 1983) do espadarte, e da composição percentual das principais espécies em relação ao desembarque total, pretende-se estudar a variação temporal das capturas desta pescaria na costa sudeste/sul do Brasil. A partir do mapeamento da dinâmica temporal e espacial da frota de espinhel de superfície, são geradas informações fundamentais para melhorar o entendimento da dinâmica da pescaria e da população de espadarte no Atlântico Sul.

\section{MATERIAL E MÉTODOS}

Os dados de captura e esforço de pesca foram obtidos através de entrevistas realizadas com os mestres das embarcações nos píers de descarregamento de Itajaí e Navegantes (SC), entre julho de 2000 e dezembro de 2001.
Esta entrevista contém informações sobre as características do espinhel (e.g. material da linha, profundidade dos anzóis), o esforço de pesca (e.g. número de anzóis por lance, dias de pesca), e a captura total da viagem por espécie, além das áreas de pesca visitadas (transformadas em coordenadas geográficas). No total foram analisadas 14 entrevistas referentes ao $2^{\circ}$ semestre de 2000 e 72 referentes a 2001 (Tab. 1). Estas entrevistas correspondem respectivamente à cerca de $20 \%$ e $75 \%$ do total desembarcado no período amostrado em 2000 e em 2001 (CTTMar/ UNIVALI, 2001 e 2002). Os dados de 2000 foram agrupados em um único lote devido ao pequeno número de amostras. No entanto, os dados de 2001 puderam ser divididos e analisados trimestralmente.

Por não haver dados de captura por lance na entrevista, a captura total de espadarte de cada embarcação $(\mathrm{kg})$ foi repartida entre as

Tabela 1 - Número de entrevistas realizadas com os mestres nos portos de Itajaí e Navegantes (SC) no segundo semestre de 2000 e em 2001.

\begin{tabular}{ccc}
\hline \hline ANO & MÊS & № DE ENTREVISTAS \\
\hline 2000 & Julho & 1 \\
& Agosto & 0 \\
& Setembro & 0 \\
& Outubro & 0 \\
& Novembro & 8 \\
& Dezembro & 5 \\
\hline TOTAL & & 14 \\
\hline 2001 & Janeiro & 3 \\
& Fevereiro & 4 \\
& Março & 8 \\
& Abril & 7 \\
& Maio & 5 \\
& Junho & 7 \\
& Julho & 7 \\
& Agosto & 8 \\
& Setembro & 5 \\
& Outubro & 6 \\
& Novembro & 7 \\
& Dezembro & 5 \\
\hline TOTAL & & 72 \\
\hline \hline
\end{tabular}


diferentes áreas visitadas pela mesma, proporcionalmente ao número de dias de pesca em cada área. O esforço $(f)$ foi calculado em dias de pesca com 1000 anzóis da seguinte forma:

$$
f=\frac{N A L \times D P}{1000}
$$

onde NAL é o número total de anzóis por lance realizado, e DPé o número de dias de pesca. Convém salientar que somente um lance é realizado por dia de pesca.

O cálculo das CPUEs ( $U$ ) por viagem foi realizado simplesmente pela divisão da captura total pelo esforço, e tem, portanto, a unidade: kg/dia de pesca com 1000 anzóis. A distribuição espacial das CPUEs foi realizada através de mapas com resolução de $5^{\circ} \times 5^{\circ}$, de acordo com recomendações da ICCAT. Neste caso, as CPUEs foram calculadas através da média ponderada dos valores de captura e esforço padrão por viagem em cada quadrado do mapa, de acordo com os procedimentos sugeridos por Quinn et al (1982). Portanto, a estimativa de CPUE ( $\hat{U})$ para uma dada área e trimestre/semestre é:

$$
\hat{U}=\sum_{i=1}^{n} C_{i} / \sum_{i=1}^{n} f_{i}
$$

onde $C$ é a captura. Este é um método alternativo utilizado para o cálculo da CPUE, quando abordagens mais complexas (e.g. CPUE ponderada pela área ocupada pelo estoque) não podem ser utilizadas (Quinn et al, 1982).

\section{RESULTADOS}

As nove embarcações espinheleiras que foram amostradas nos portos de Itajaí e
Navegantes (SC) em 2000, direcionaram seus esforços para latitudes entre 25-35ㅇ e principalmente para regiões com profundidades superiores a 1000 metros (Fig. 1). As distribuições das capturas refletem basicamente os padrões de distribuição do esforço de pesca, com as menores capturas ocorrendo em regiões mais costeiras (com menos de $1000 \mathrm{~m}$ de profundidade). As distribuições das CPUEs tenderam a ser maiores mais ao sul (latitudes superiores a $30^{\circ}$ S), e em maiores profundidades (Fig. 1).

Durante o ano de 2001, vinte e duas embarcações espinheleiras concentraram seus esforços geralmente em áreas entre 25-35으/ 45-55W (Fig. 2). No entanto a região mais ao sul, em frente a costa da Argentina, também foi visitada com razoável frequência. $O 1^{\circ}$ trimestre foi o que apresentou maior amplitude no que diz respeito às áreas de pesca visitadas, com um barco atuando próximo ao arquipélago de Vitória-Trindade, e vários outros atuando em regiões oceânicas do Uruguai, Argentina, e próximo às Ilhas Malvinas. No $4^{\circ}$ trimestre também ocorreram esforços em pontos próximos da elevação do Rio Grande (30요 35ํW) (Fig. 2).

No geral destaca-se a área delimitada pelas latitudes de $30^{\circ}-35^{\circ}$ S e longitudes de $45^{\circ-}$ $50^{\circ} \mathrm{W}$, que sempre propiciou capturas relativamente elevadas em diferentes épocas do ano (Fig. 3).

No $1^{\circ}$ trimestre de 2001 as CPUEs mais altas foram obtidas principalmente em regiões mais oceânicas, próximas da cadeia de montanhas submersas de Vitória-Trindade, e ao largo da costa sul do Brasil e norte da Argentina entre $30^{\circ}-40^{\circ} \mathrm{S}$ (Fig. 4). No $2^{\circ}$ trimestre novamente as áreas mais oceânicas foram as que apresentaram maiores CPUEs, quando comparadas com áreas mais costeiras. No $3^{\circ}$ trimestre esse padrão só pôde ser constatado entre $25^{\circ}-30^{\circ}$ S. No $4^{\circ}$ trimestre não ocorreram CPUEs superiores a $200 \mathrm{~kg} /$ dia de pesca com 1000 anzóis, ao contrário do ocorrido nos demais trimestres, e os valores 

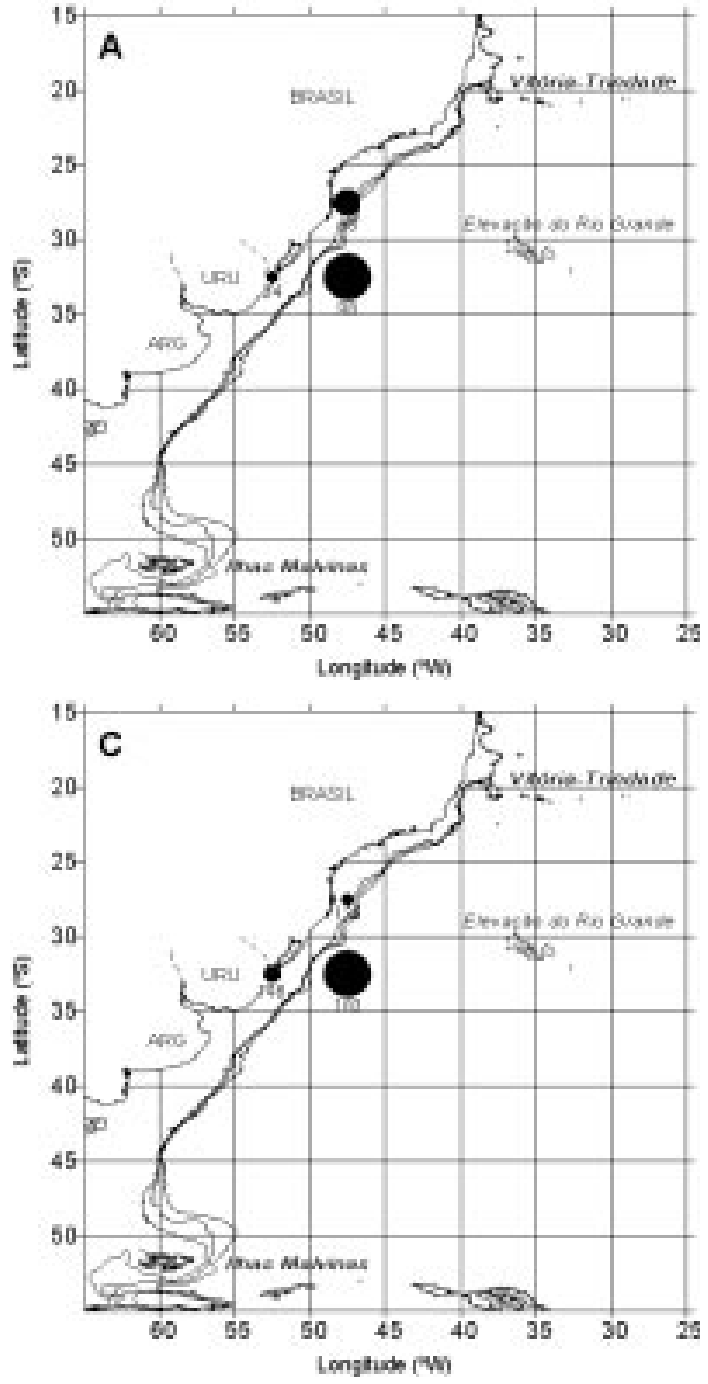

próximos à costa foram um pouco superiores aos obtidos em áreas mais oceânicas.

A maioria das capturas de espadarte por viagem no $2^{\circ}$ semestre de 2000 foram de cerca de $1,5 \mathrm{t}$ (Fig. 5). Nos dois primeiros trimestres de 2001 as capturas mais freqüentes foram baixas com moda em torno de $0,5 \mathrm{t}$, enquanto que no segundo semestre, capturas maiores ( $\approx 2,5 \mathrm{t}$ ) foram mais freqüentes (Fig. 6).

As CPUEs mais comuns no $2^{\circ}$ semestre de 2000 foram de cerca de $120 \mathrm{~kg} /$ dia de pesca com 1000 anzóis (Fig. 7). Em

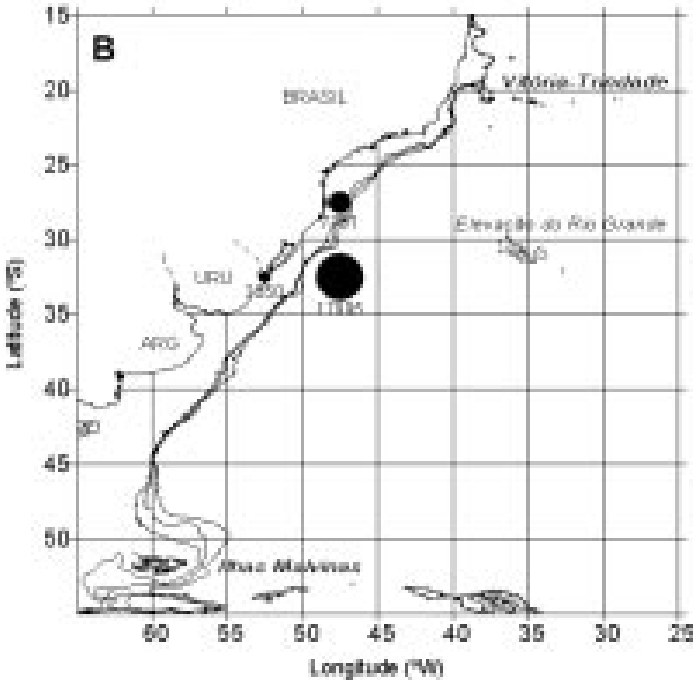

Figura 1 - Distribuição geográfica: (A) do esforço de pesca (valores abaixo dos círculos - dias de pesca com 1000 anzóis), (B) da captura (valores abaixo dos círculos - quilogramas), e (C) da CPUE (valores abaixo dos círculos - kg/dia de pesca com 1000 anzóis) de espadarte (Xiphias gladius), obtidos pela frota espinheleira de Santa Catarina no $2^{\circ}$ semestre de 2000 . As linhas contínuas na área oceânica, paralelas à linha de costa, representam as isóbatas de 200, 500 e 1000 metros de profundidade.

2001, a moda das CPUEs foi baixa nos dois primeiros trimestres (em torno de $40 \mathrm{~kg} / \mathrm{dia}$ de pesca com 1000 anzóis), e um pouco mais elevada nos dois últimos trimestres $(120 \mathrm{~kg} /$ dia de pesca com 1000 anzóis) (Fig. 8). É importante mencionar que houve um único registro de CPUE fora dos padrões, com mais de $1000 \mathrm{~kg} /$ dia de pesca com 1000 anzóis no segundo trimestre que não está representado na Figura 8, assim como a captura referente a esse registro (15 t.) não foi representada na Figura 6.

A contribuição percentual do espadarte para o desembarque total por viagem dos espinheleiros de Itajaí (SC) no $2^{\circ}$ semestre de 2000 girou em torno de 15\% (Fig. 9). Em 2001 

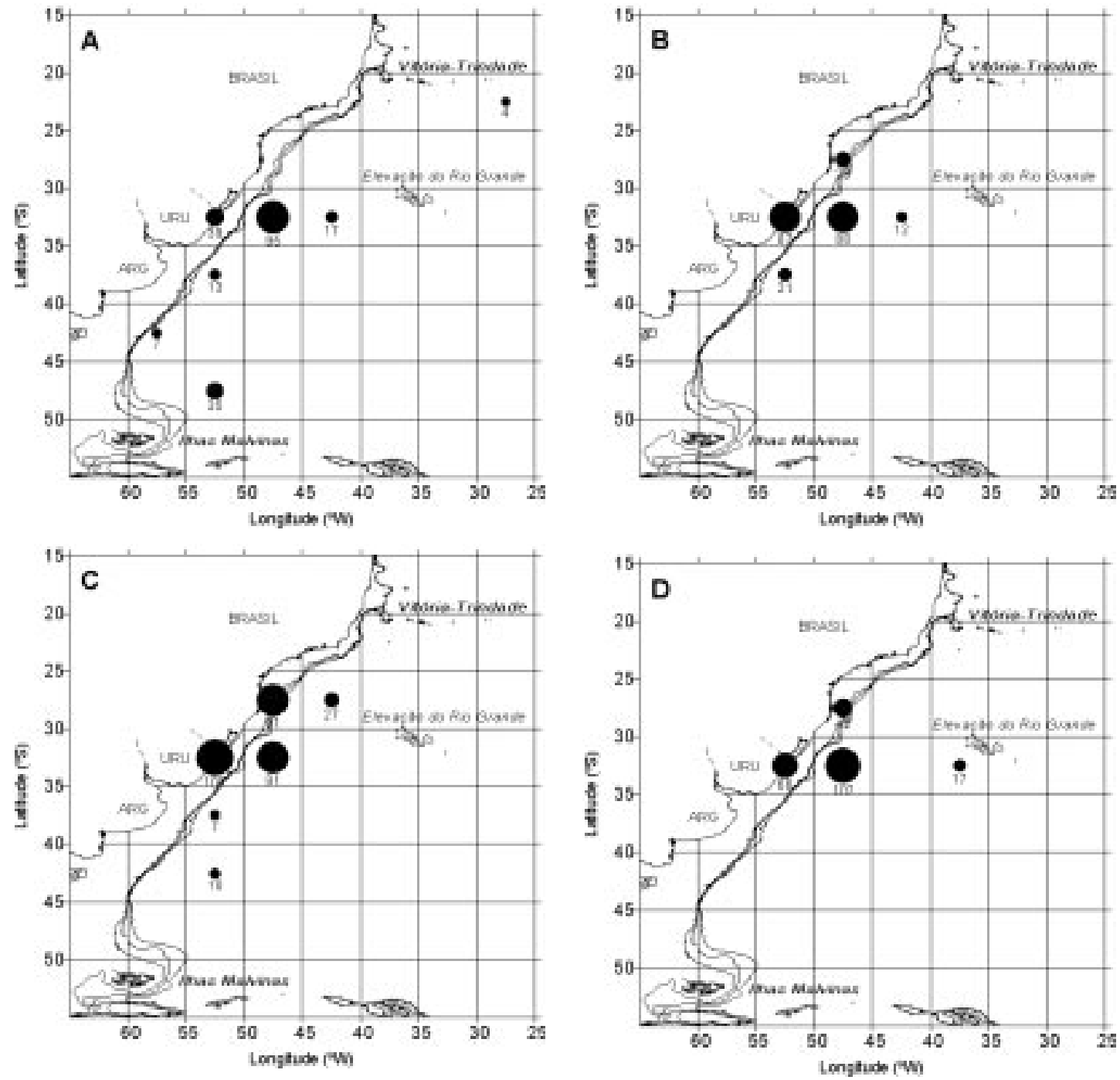

Figura 2 - Distribuição geográfica do esforço de pesca (valores abaixo dos círculos - dias de pesca com 1000 anzóis) de espadarte (Xiphias gladius) obtido pela frota espinheleira de Santa Catarina no ano de 2001 . (A) $1^{\circ}$. trimestre, $(B) 2^{\circ}$ trimestre, (C) $3^{\circ}$ trimestre, e (D) $4^{\circ}$ trimestre. As linhas contínuas na área oceânica, paralelas à linha de costa, representam as isóbatas de 200, 500 e 1000 metros de profundidade.

os valores da contribuição percentual tenderam a aumentar ao longo dos trimestres, passando de uma moda de cerca de $5 \%$ no primeiro, para $25 \%$ no quarto trimestre (Fig. 10). O $2^{\circ}$ e o $4^{\circ}$ trimestre foram os que apresentaram maior amplitude entre as distribuições de freqüência da contribuição de espadarte, que chegou a atingir até mais de $40 \%$ do total capturado (Fig. 10B e 10D). No geral o espadarte contribuiu em média com $18 \%$ do total desembarcado no 2o semestre de 2000, e com 17\% em 2001. Além do espadarte, as principais espécies desembarcadas pelos espinheleiros foram, a albacora-bandolim (Thunnus obesus), a 

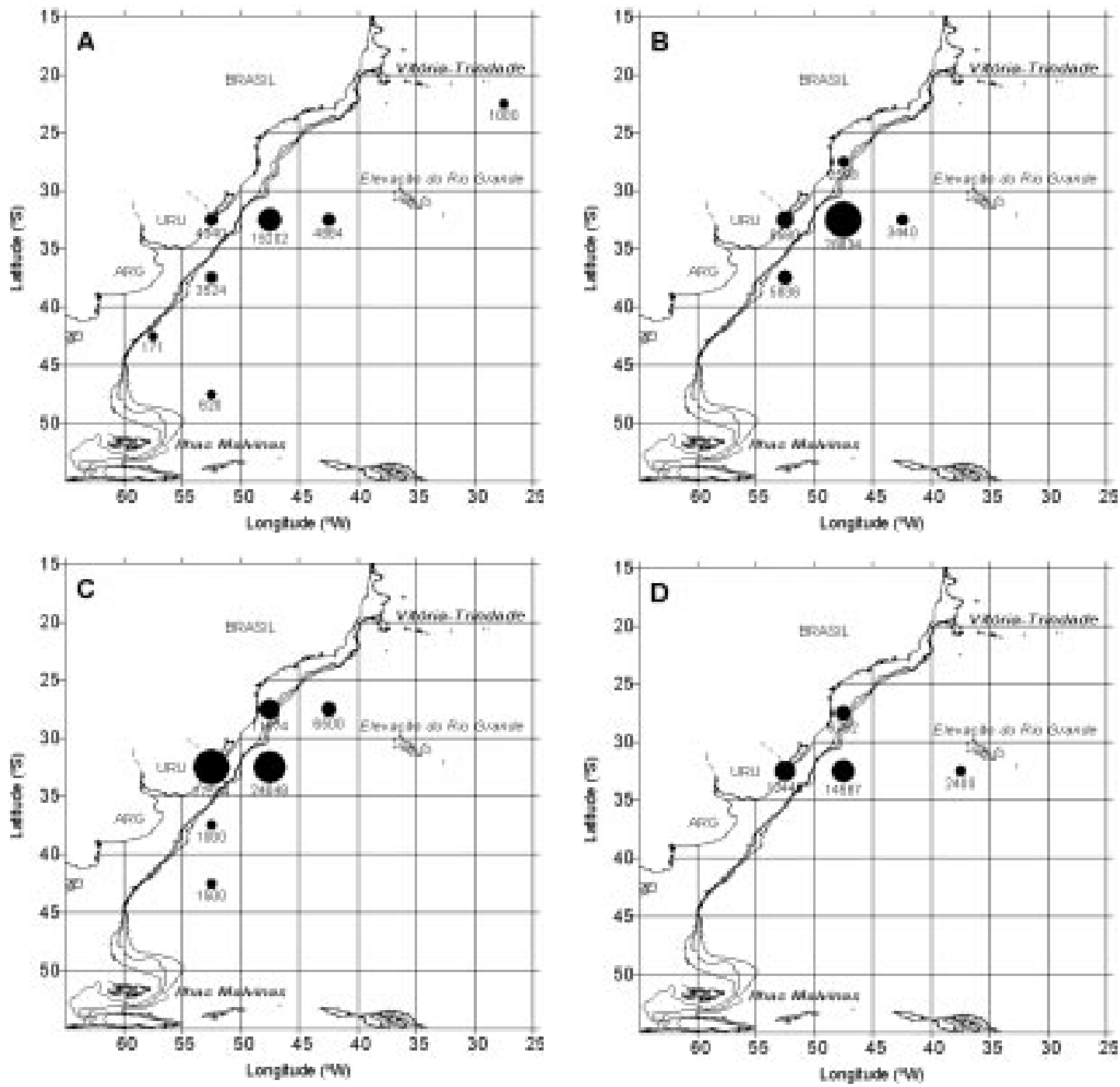

Figura 3 - Distribuição geográfica da captura (valores abaixo dos círculos - quilogramas) de espadarte (Xiphias gladius) obtido pela frota espinheleira de Santa Catarina no ano de 2001. (A) $1^{\circ}$ trimestre, (B) $2^{\circ}$ trimestre, (C) $3^{\circ}$ trimestre, e (D) 4ำ trimestre. As linhas contínuas na área oceânica, paralelas à linha de costa, representam as isóbatas de 200, 500 e 1000 metros de profundidade.

albacora-branca (Thunnus alalunga), a albacora-lage (Thunnus albacares), e principalmente o cação-azul (Prionace glauca) (Tab. 2). Merece também menção o fato de que das vinte e duas embarcações que foram amostradas em 2001, cinco atuaram em regiões mais ao norte (latitudes inferiores a $25^{\circ} \mathrm{S}$ ), e não apresentaram espadarte em seus desembarques. Nestes casos o dourado (Coryphaena hippurus) representou quase 100\% das capturas.

Em 2001, as maiores capturas foram de cação-azul. Com exceção deste, as capturas das principais espécies tendem a aumentar 

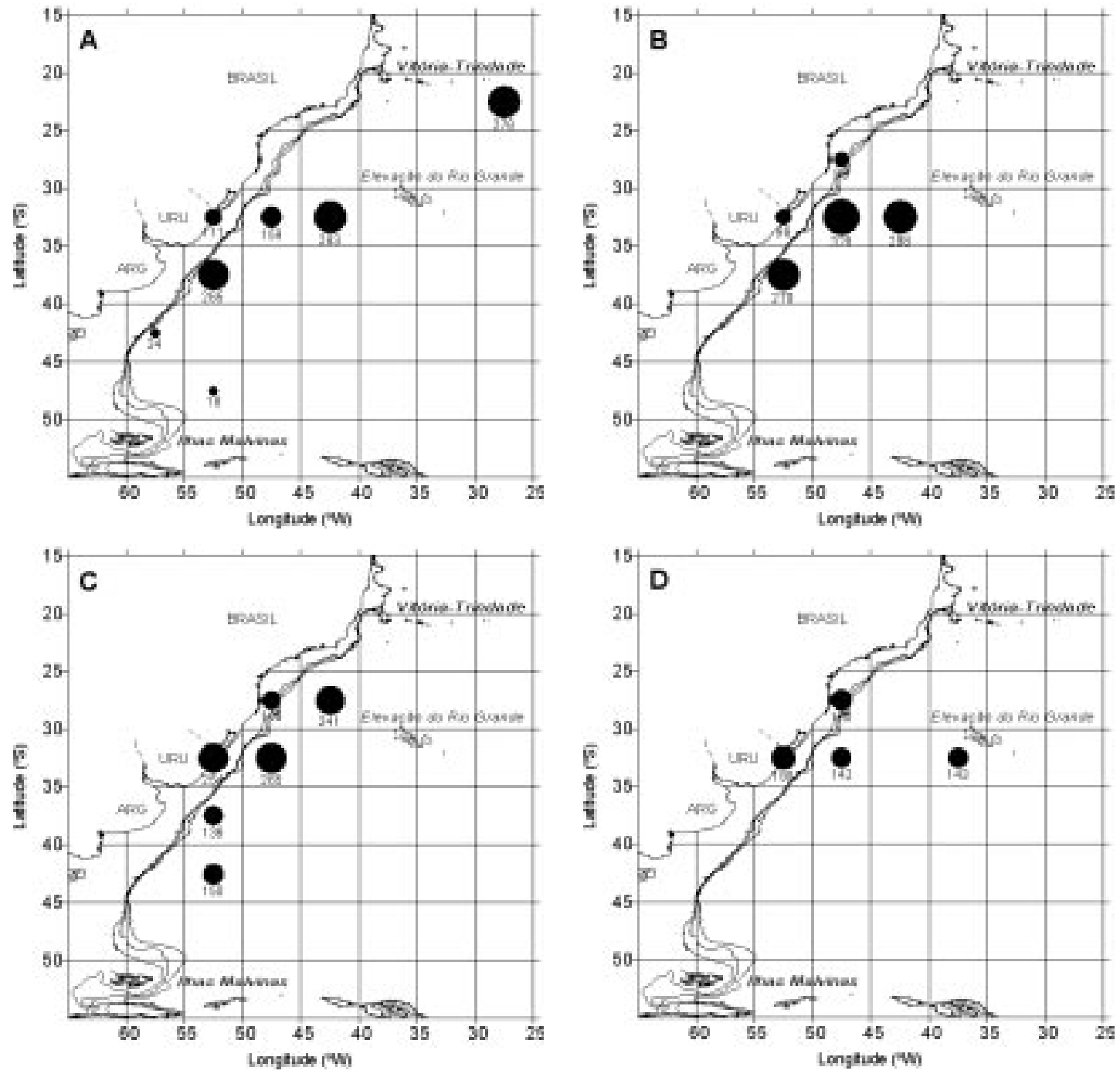

Figura 4 - Distribuição geográfica da CPUE (valores abaixo dos círculos - kg/dia de pesca com 1000 anzóis) de espadarte (Xiphias gladius) obtido pela frota espinheleira de Santa Catarina no ano de 2001. (A) $1^{\circ}$ trimestre, (B) $2^{\circ}$ trimestre, (C) 3ํㅡㄹ trimestre, e (D) $4^{\circ}$ trimestre. As linhas contínuas na área oceânica, paralelas à linha de costa, representam as isóbatas de 200, 500 e 1000 metros de profundidade.

gradativamente até o $3^{\circ}$ trimestre, voltando a decrescer no $4^{\circ}$ trimestre (Tab. 2). A contribuição percentual de cada espécie para o desembarque total, geralmente segue este mesmo padrão. Observa-se que há um predomínio de cação azul no $1^{\circ}$ trimestre
( $\approx 1 \%)$, seguido de uma queda progressiva até o 4으 ( $\approx 32 \%)$. No geral, o espadarte apresentou um padrão inverso, mas com menor amplitude de variação, aumentando sua contribuição do $1^{\circ}(\approx 12 \%)$ para o $4^{\circ}$ trimestre ( $\left.\approx 22 \%\right)$ (Tab. 2$)$. 


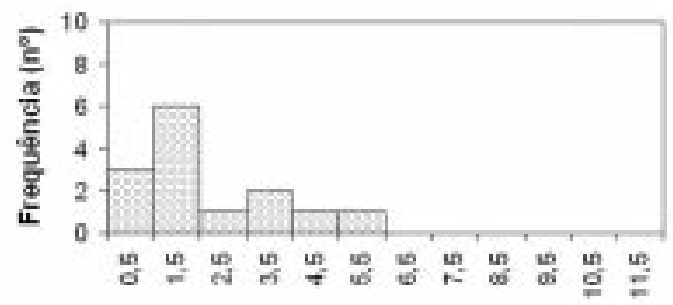

Captura (ton)

Figura 5 - Distribuição de frequência para a captura (toneladas) de espadarte (Xiphias gladius) por viagem no $2^{\circ}$ semestre de 2000.

\section{DISCUSSÃO}

Não ocorreram diferenças marcantes entre os padrões gerais de distribuição do esforço, da captura e da CPUE encontrados no segundo semestre de 2000 e de 2001 . A semelhança entre os dois períodos indica que apesar de haver alguma variabilidade interanual, as interpretações e análises do padrão de pesca de um ano podem ser estendidas ao outro. Portanto as discussões foram centradas em 2001, em virtude da maior riqueza de detalhe da base de dados.

A tendência de que a frota explore menos as regiões mais oceânicas e/ou distantes do porto base (Itajaí-SC) é uma constante ao longo do ano (Fig. 2). Essa estratégia se mostrou inadequada pelo menos para os dois primeiros trimestres, quando claramente as áreas mais oceânicas, com maiores CPUEs, acabaram sendo pouco exploradas. Neste período, as áreas onde a frota concentrou esforço (em frente à costa sul do Brasil entre $\left.30^{\circ}-35^{\circ} \mathrm{S}\right)$, apresentaram CPUEs mais reduzidas (Fig. 4). No entanto, as CPUEs nas áreas costeiras são comparáveis às de áreas mais oceânicas ao sul de $30^{\circ} \mathrm{S}$ no $3^{\circ}$ trimestre e ao longo de todo - 4 trimestre. Nestes casos há boa sobreposição entre as áreas de maior concentração do esforço de pesca e as de maior CPUE (Figs. 2 e 4).

O ciclo de rentabilidade do espadarte, com maiores rendimentos na área sudeste/sul
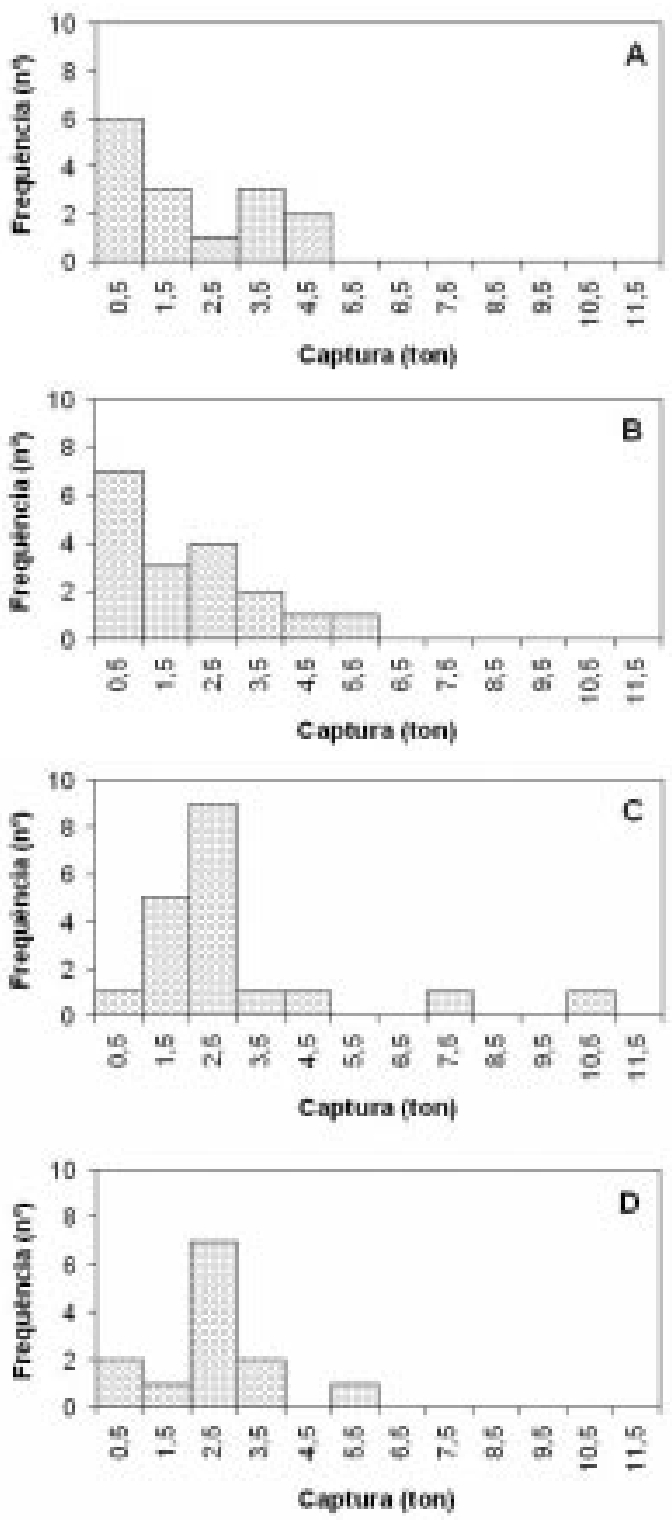

Figura 6 - Distribuição de frequência para a captura (toneladas) de espadarte (Xiphias gladius) por viagem em 2001. (A) $1^{\circ}$ trimestre; (B) $2^{\circ}$ trimestre; (C) $3^{\circ}$ trimestre, (D) $4^{\circ}$ trimestre.

do Brasil principalmente no $2^{\circ}$ e $3^{\circ}$ trimestre (Fig. 3), afeta o padrão de distribuição do esforço de pesca da frota nacional, e aparentemente mais ainda o da frota arrendada. Meneses de Lima et al (2000) citam que os 


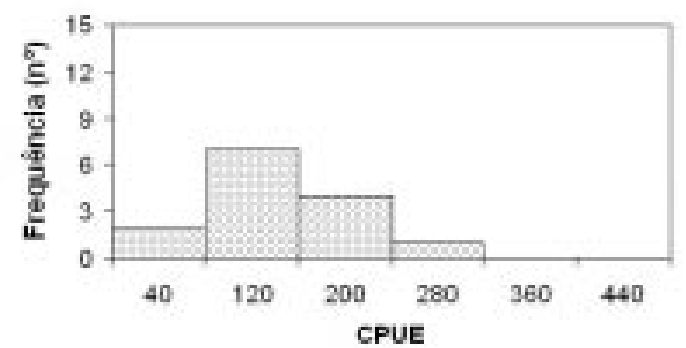

Figura 7 - Distribuição de freqüência para a CPUE (kg/dia de pesca com 1000 anzóis) de espadarte (Xiphias gladius) no $2^{\circ}$ semestre de 2000 .

movimentos da frota arrendada são mais flexíveis, sendo que ela se concentra nas regiões de pesca do sudeste/sul entre maio e outubro e posteriormente tende a direcionar 0 esforço para o nordeste de novembro a abril. Estes autores destacam essa plasticidade na distribuição do esforço de pesca da frota arrendada como uma das causas da maior eficiência de captura em relação à frota nacional, que sempre opera mais perto do porto base. No entanto, aparentemente não é tão necessário esse deslocamento para a costa norte/nordeste do Brasil para se obter boas rentabilidades no verão. $O$ simples deslocamento para regiões mais oceânicas na costa sudeste/sul, já seria suficiente para

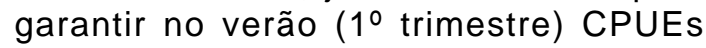
semelhantes ou próximas das que se obtém em outros períodos mais rentáveis do ano (e.g 2o e $3^{\circ}$ trimestres) (Fig. 4).

A tendência de que as CPUEs na costa sudeste/sul do Brasil sejam maiores em áreas mais oceânicas do que nas costeiras nas imediações do verão, pode ser interpretada como uma consequência do aumento notório da influência da Corrente do Brasil em áreas costeiras durante essa estação do ano. Consequentemente diminui a influência da Corrente das Malvinas (predominante no inverno em áreas costeiras da região sul do Brasil) (Garcia, 1997), na qual existe associada uma grande concentração de lulas (Haimovici \& Perez, 1990). Estes cefalópodos são o principal item alimentar do espadarte no sudoeste do
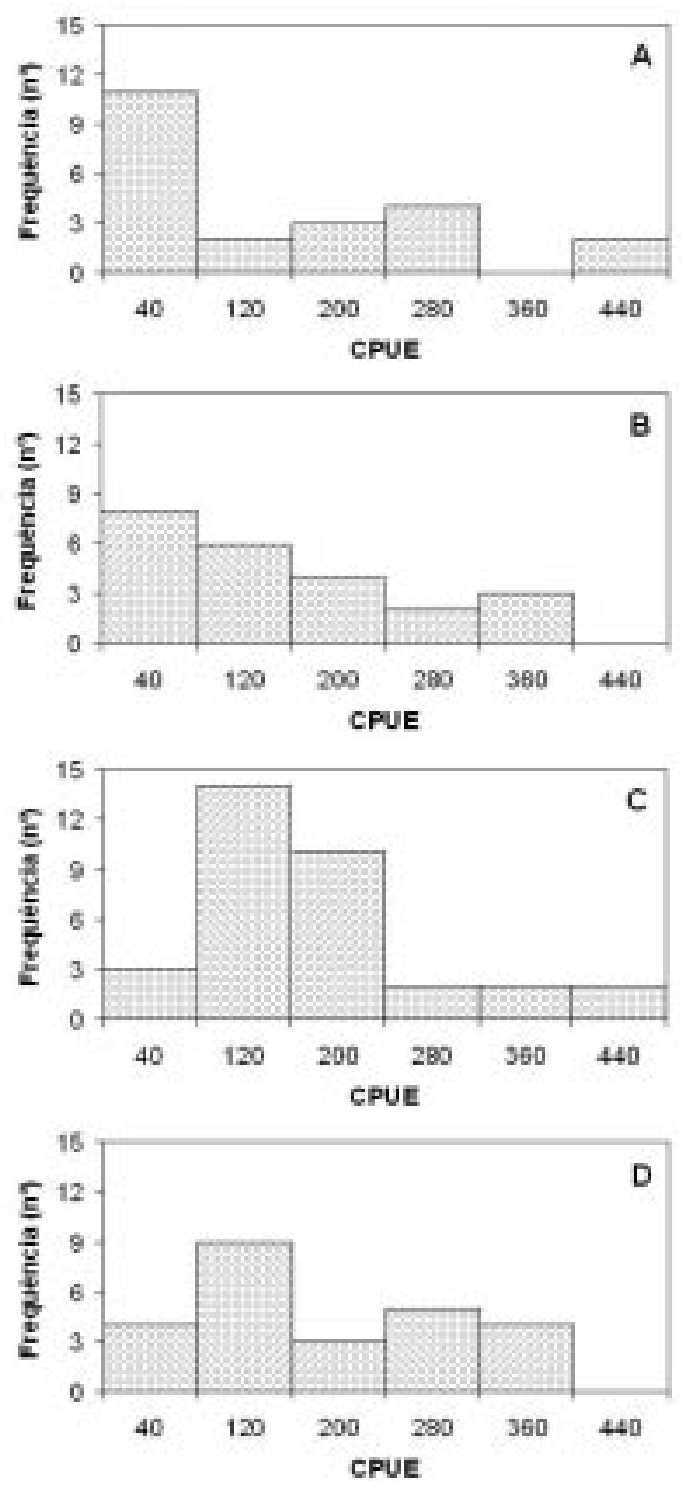

Figura 8 - Distribuição de freqüência para a CPUE (kg/dia de pesca com 1000 anzóis) de espadarte (Xiphias gladius) em 2001. (A) $1^{\circ}$ trimestre, (B) $2^{\circ}$ trimestre, (C); 3ำ trimestre, (D) 4ํㅡㄴ trimestre.

Atlântico (Zavala-Camin, 1987). Portanto, a migração desta espécie deve ter caráter trófico e estaria associada à distribuição das lulas nesta região (Arfelli, 1996), o que justificaria as CPUEs mais baixas em regiões costeiras 


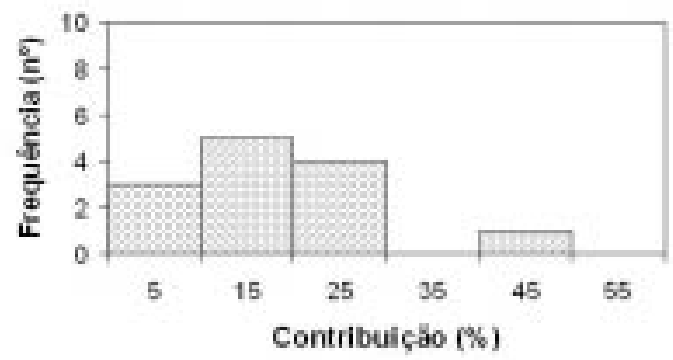

Figura 9 - Distribuição de freqüência da contribuição percentual (\%) de espadarte (Xiphias gladius) para o captura por viagem no $2^{\circ}$ semestre de 2000.

durante o verão. Maiores considerações sobre essa questão não seriam adequadas, dado o objetivo deste trabalho. No entanto, a possibilidade de conexão entre as variações sazonais oceanográficas de meso-escala e a vulnerabilidade do espadarte à pescaria, merece investigações futuras.

A tendência de deslocamento para a direita das modas das distribuições de frequência da captura do $1^{\circ}$ ao $4^{\circ}$ trimestre, pode ser interpretada como uma conseqüência de um incremento na densidade, vulnerabilidade e/ou comprimento médio nas regiões usualmente exploradas (e.g. áreas costeiras) nos meses de inverno e primavera.

No $1^{\circ}$ trimestre as áreas com CPUEs elevadas (Fig. 4) foram visitadas raramente (Fig. 2), de forma que há um predomínio de CPUEs baixas nesse trimestre do ano (Fig. 8). Nitidamente há uma maior freqüência de CPUEs maiores nas viagens de pesca realizadas no $2^{\circ}$ semestre de 2001 (Fig. 8). No caso do $4^{\circ}$ trimestre, a moda para valores altos de captura por viagem (Fig. 6) não pode ser explicada por um incremento sazonal na vulnerabilidade e/ ou densidade pois as CPUEs nesse trimestre, são em alguns casos até menores aos dos demais trimestres (Fig. 4). A questão é que apesar de não serem muito elevadas, pelo menos não ocorreram também muitas CPUEs extremamente baixas como no $1^{\circ}$ e no $2^{\circ}$ trimestre (Fig. 4). É aparente que o padrão de maior frequência de CPUEs altas no segundo
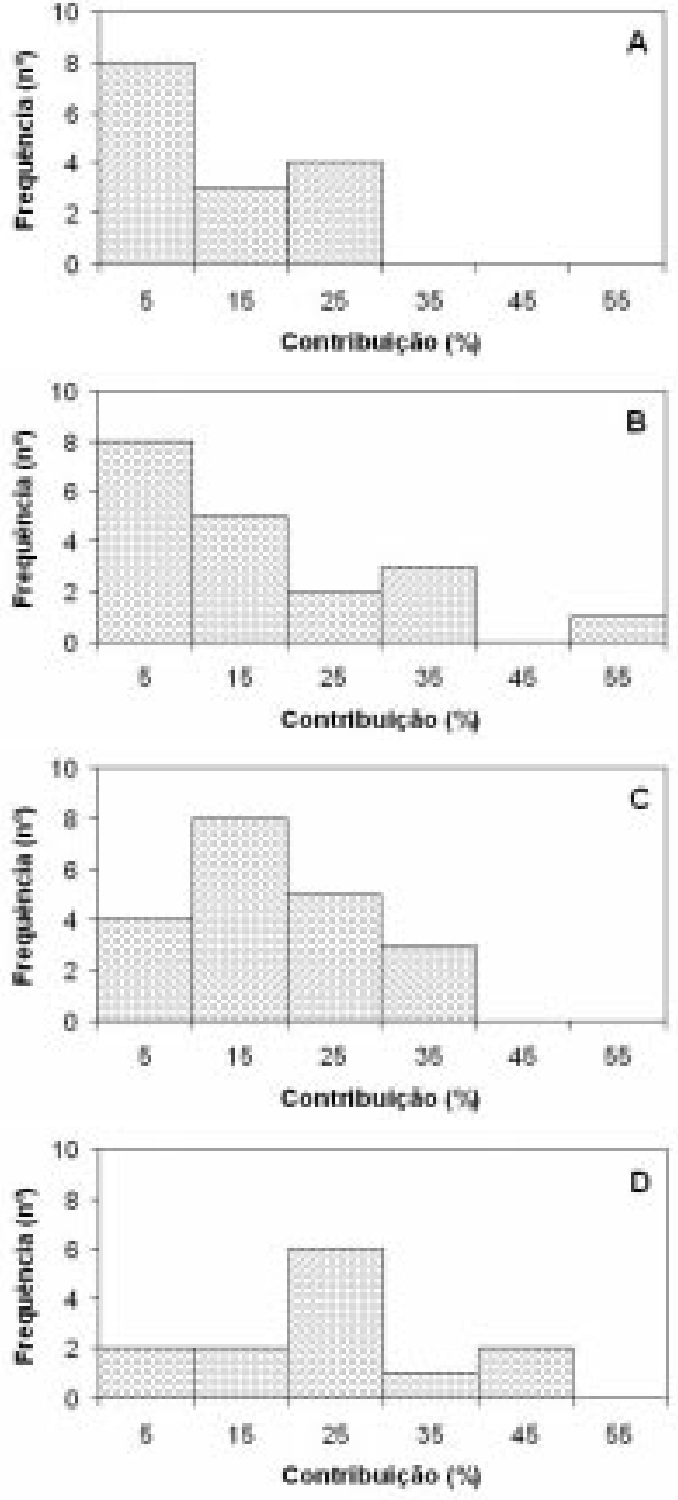

Figura 10 - Distribuição de freqüência da contribuição percentual (\%) de espadarte (Xiphias gladius) para 0 captura por viagem em 2001. (A) $1^{\circ}$ trimestre, (B) $2^{\circ}$ trimestre, (C), $3^{\circ}$ trimestre, (D) 4ำ trimestre.

semestre é mero fruto de que nesse período a diferença de rentabilidade entre a região oceânica (normalmente com maiores CPUEs) e a região costeira (mais visitada), é menor nesse período do ano. 
MAYER \& ANDRADE: A pesca do espadarte em Santa Catarina.

Tabela 2 - Captura total $(\mathrm{kg})$ e contribuição percentual (\%) para o desembarque total das principais espécies capturadas pela frota de espinhel de superfície de Santa Catarina em 2001, por trimestre.

\begin{tabular}{|c|c|c|c|c|c|}
\hline \multicolumn{6}{|c|}{ TRIMESTRE } \\
\hline ESPÉCIE & $I$ & II & III & $\overline{\text { IV }}$ & TOTAL $(\mathrm{kg})$ \\
\hline \multirow{2}{*}{ Espadarte } & $29720 \mathrm{~kg}$ & $49284 \mathrm{~kg}$ & $72276 \mathrm{~kg}$ & $36177 \mathrm{~kg}$ & \multirow{2}{*}{187457} \\
\hline & $12,45 \%$ & $17,47 \%$ & $14,40 \%$ & $22,36 \%$ & \\
\hline \multirow{2}{*}{ Cação azul } & $195050 \mathrm{~kg}$ & $119003 \mathrm{~kg}$ & $177311 \mathrm{~kg}$ & $53188 \mathrm{~kg}$ & \multirow{2}{*}{544552} \\
\hline & $81,73 \%$ & $42,19 \%$ & $35,32 \%$ & $32,87 \%$ & \\
\hline \multirow{2}{*}{ Albacora lage } & $3911 \mathrm{~kg}$ & $22128 \mathrm{~kg}$ & $78814 \mathrm{~kg}$ & $18374 \mathrm{~kg}$ & \multirow{2}{*}{123227} \\
\hline & $1,64 \%$ & $7,84 \%$ & $15,70 \%$ & $11,36 \%$ & \\
\hline \multirow{2}{*}{ Albacora branca } & $1354 \mathrm{~kg}$ & $40042 \mathrm{~kg}$ & $69101 \mathrm{~kg}$ & $2891 \mathrm{~kg}$ & \multirow{2}{*}{113388} \\
\hline & $0,57 \%$ & $14,19 \%$ & $13,77 \%$ & $1,79 \%$ & \\
\hline \multirow{2}{*}{ Albacora bandolim } & $2157 \mathrm{~kg}$ & $18811 \mathrm{~kg}$ & $69727 \mathrm{~kg}$ & $3454 \mathrm{~kg}$ & \multirow{2}{*}{94149} \\
\hline & $0,90 \%$ & $6,67 \%$ & $13,89 \%$ & $2,13 \%$ & \\
\hline \multirow{2}{*}{ Outros } & $6456 \mathrm{~kg}$ & $32829 \mathrm{~kg}$ & $34771 \mathrm{~kg}$ & $47718 \mathrm{~kg}$ & \multirow{2}{*}{121774} \\
\hline & $2,71 \%$ & $11,64 \%$ & $6,93 \%$ & $29,49 \%$ & \\
\hline TOTAL (kg) & 238648 & 282097 & 502000 & 161802 & 1184547 \\
\hline
\end{tabular}

As distribuições de freqüência de capturas, CPUEs e mesmo da contribuição percentual de espadarte, não se assemelham a uma distribuição normal (Figs. 5 a 10). Portanto, estimativas dessas quantidades a partir de cálculos de médias aritméticas podem ser um equívoco. Esse alerta é útil quando há necessidade de se fazer projeções ou mesmo tomar decisões com base em estimativas de rentabilidade por área e trimestre por exemplo.

Se considerarmos que o peso médio por peça capturada é de cerca de $35 \mathrm{~kg}$, as CPUEs obtidas são muito baixas (Figs. 7 e 8), indicando que normalmente são capturados de 3 a 5 espadartes/dia de pesca com 1000 anzóis. Ainda assim, esta pescaria continua a ser rentável para os pescadores devido ao elevado valor econômico desta espécie no mercado externo.

Independentemente da época do ano, a captura de cação azul é sempre maior que a das outras espécies, e demonstra grande variação do $1^{\circ}$ ao $4^{\circ}$ trimestre. No $3^{\circ}$ trimestre observa-se um aumento no volume desembarcado de espadarte, indicando que esse período parece ser realmente o que apresenta maior densidade e/ou vulnerabilidade de espadarte nas regiões costeiras do sudeste/ sul (Tab. 2), como já foi relatado em trabalhos anteriores (e.g. Arfelli, 1996). No entanto, a contribuição percentual desta espécie para o total desembarcado é maior no $4^{\circ}$, e não no $3^{\circ}$ trimestre. A contribuição percentual elevada no $4^{\circ}$ trimestre está associada à queda da contribuição das albacoras (principalmente a albacora-branca e a albacora-bandolim), e até mesmo do cação-azul.

O decréscimo de cação azul nas capturas provavelmente não está relacionado a deslocamentos da frota ao longo do ano, uma vez que a área entre $30^{\circ}-35^{\circ} \mathrm{S} / 45^{\circ}-55^{\circ} \mathrm{W}$ foi sempre a que concentrou os maiores esforços de pesca independente da época do ano (Fig. 2). Nesse caso, é então mais provável que a vulnerabilidade do cação azul para a pesca de espinhel de superfície, tenha uma variabilidade sazonal grande, o que justificaria o padrão observado (Tab. 2). Nesse caso, o cenário de verão, em que há uma maior influência da Corrente do Brasil junto à região da plataforma continental (Castello \& Möller, 1977; Matsuura, 1986; Garcia, 1997), seria favorável a um aumento da densidade e/ou vulnerabilidade do cação-azul. Essa questão é colocada aqui em caráter de especulação, e certamente merece maiores investigações no futuro.

As albacoras são também visadas pelos pescadores pelo preço relativamente elevado. 
As capturas dessas espécies são mais altas no $3^{\circ}$ trimestre (Tab. 2), demonstrando que não apenas para o espadarte esse período é mais propício para a pesca de espinhel pelágico. Os padrões extremamente semelhantes das variações da contribuição percentual da albacora-branca e da albacora-bandolim chamam a atenção (Tab. 2). Seria interessante verificar no futuro, à medida que mais dados forem coletados, se há algum tipo de associação entre a captura dessas espécies na costa sudeste/sul do Brasil.

As capturas de espadarte mostraram um grande incremento nas composições percentuais desde o final da década de 1970 , atingindo um pico de $45,1 \%$ do total capturado em 1980. Posteriormente houve um declínio atingindo um mínimo de $13,3 \%$ em 1984 . No período entre 1987 e 1996 a contribuição percentual de espadarte chegou a atingir um pico de $37 \%$ em 1995, ultrapassando em muito as demais espécies de tunídeos. No entanto, foi ainda inferior à composição percentual dos tubarões (47\%). Em 1997, a contribuição percentual do espadarte para a captura total brasileira atingiu um clímax e chegou a representar cerca de $50 \%$ da captura em peso da frota nacional, enquanto que os tubarões representaram cerca de $35 \%$. Na frota arrendada, durante o mesmo período, o espadarte representou $41,4 \%$ e os tubarões $14,5 \%$ do total capturado (Meneses de Lima et al, 2000). O cenário que encontramos para a frota nacional na região sudeste/sul não é coerente com essa tendência de aumento na contribuição de espadarte observada no final da década de 1990, sendo que a contribuição do espadarte girou em torno de somente $17 \%$ em 2001 (Tab. 2).

Um vício que poderia estar inserido na análise da contribuição percentual, seria o limite de captura de espadarte imposto para os barcos arrendados, que não deveria ultrapassar 15\% da captura total. Neste trabalho, no entanto, 0 número de barcos arrendados amostrados (apenas dois, totalizando oito amostragens durante 2000 e 2001), provavelmente não foi suficiente para inserir erros significativos na contribuição percentual. De qualquer forma, as variações percentuais observadas não podem ser interpretadas como derivadas das variações das populações explotadas. Em pescarias multiespecíficas as variações dos volumes capturados são bastante afetadas por mudanças nas estratégias dos pescadores. Além do já referido direcionamento da frota no final da década de 1990 para a captura de espadarte, há ainda um agravante derivado do descarte de itens de menor interesse comercial. Por exemplo, as carcaças de elasmobrânquios foram em alguns casos descartadas, enquanto que somente as barbatanas (com alto valor no mercado internacional) eram mantidas. Ainda que não registrado oficialmente, há um consenso de que em vários períodos da pescaria houveram enormes descartes de elasmobrânquios. As oscilações da quantidade de descarte em virtude de pressões fiscais e econômicas de mercado, inserem um vício na série temporal de distribuição percentual de captura por espécie. Correções para os períodos em que os vícios foram inseridos são impossíveis em virtude das poucas informações quantitativas disponíveis.

O monitoramento da pescaria continuará a ser feito nos próximos anos e espera-se que algumas hipóteses levantadas neste trabalho, principalmente a que diz respeito sobre a existência de maiores rentabilidades em áreas mais oceânicas, possam ser gradativamente consolidadas. De qualquer forma, esse primeiro mapeamento realizado fica como referência para comparações com o futuro dessa pescaria, que deverá sofrer algumas alterações nos próximos anos devido à nova política pesqueira adotada pelo governo brasileiro. Como exemplo de mudanças que poderão surgir, podemos citar a criação de uma nova Instrução Normativa (I.N. 3/2003), regulamentando a pescaria brasileira de atuns e afins e publicada em 19 de setembro de 2003, que estabelece limites de captura para diversas 
espécies, entre elas o espadarte (ICCAT, 2003). Além disso, também é provável que seja verificada a introdução de novas embarcações espinheleiras na pescaria do sudeste/sul do país, em virtude da política governamental de estímulo à pesca oceânica. O acompanhamento desse novo cenário, e mesmo uma avaliação da magnitude das mudanças observadas, é facilitado a partir do diagnóstico realizado neste trabalho.

\section{REFERÊNCIAS}

Amorim, A. F. \& C. A. Arfelli. 1984. Estudo biológico-pesqueiro do espadarte, Xiphias gladius Linnaeus, 1758, no sudeste e sul do Brasil (1971 a 1981). Bol. Inst. Pesca. 11:35-62.

Arfelli, C. A. 1996. Estudo da Pesca e Aspectos da Dinâmica Populacional de Espadarte, Xiphias Gladius L. 1758, no Atlântico Sul. Dissertação de Doutorado. UNESP, Rio Claro, $175 \mathrm{p}$.

Castello, J. P. \& O. O. Möller. 1977. Sobre as condições oceanográficas no Rio Grande do Sul. Atlântica. 2 (2): 25-110.

CTTMar/UNIVALI. 2001. Boletim estatístico da pesca industrial de Santa Catarina - ano 2000. Ações Prioritárias ao Desenvolvimento da Pesca e Aquicultura no Sul do Brasil. Convênio Ministério da Agricultura, Pecuária e Abastecimento (MAPA), Universidade do Vale do Itajaí (UNIVALI). MAPA/SARC/DPA/003/2001. Pezzuto, P. R. (coord.). 61 p.

CTTMar/UNIVALI. 2002. Boletim estatístico da pesca industrial de Santa Catarina - ano 2001. Ações Prioritárias ao Desenvolvimento da Pesca e Aquicultura no Sul do Brasil. Convênio Ministério da Agricultura, Pecuária e Abastecimento (MAPA), Universidade do Vale do Itajaí (UNIVALI). MAPA/SARC/DENACOOP/176/ 2002. Pezzuto, P. R. (coord.). 89 p.
Garcia, C. A. E. 1997. Physical Oceanography. In: Seeliger, U; Odebrecht, C. \& J. P. Castello (eds.). 1997. Subtropical Convergence environments. The coast and sea in the southwestern Atlantic. Springer: Germany. $308 \mathrm{p}$.

Gulland, J. A. 1983. Fish Stock Assessment A manual of Basic Methods. John Wiley \& Sons: Chichester. $223 \mathrm{p}$.

Haimovici, M. \& J. A. A. Perez. 1990. Observaciones sobre la distribución y maduración sexual del calamar argentino, Illex argentinus (Castellanos, 1960) (Cephalopoda: Ommastrephidae), en el sur del Brasil. Scient. Mar. 54 (2): 179-185.

ICCAT. 2003. Report of the Standing Committee on Research and Statistics (SCRS). ICCAT: Madrid. $201 \mathrm{p}$.

Matsuura, Y. 1986. Contribuição ao estudo da estrutura oceanográfica da região sudeste entre Cabo Frio (RJ) e Cabo de Santa Marta Grande (SC). Ciência e Cultura. 38 (8): 1439-1447.

Meneses de Lima, J. H.; Kotas, J. E \& C. F. Lin. 2000. A historical review of the brazilian longline fishery and catch of swordfish. Col. Vol. Sci. Pap., ICCAT, Madrid. SCRS/99/ 36, Vol. LI: 1329-1358.

Quinn, T. J.; Hoag, S. H. \& G. M. Southward. 1982. Comparison of two methods of combining Catch-Per-Unit-Effort data from geographic regions. Can. J. Fish. Aquat. Sci. 39: 837-846.

Zavala-Camin, L. A. 1987. Ocorrência de peixes, cefalópodos e crustáceos em estômagos de atuns e espécies afins, capturadas com espinhel no Brasil (23ㅇ - 34으) 1972 1985. Bol. Inst. Pesca. 14: 93 - 102.

Zavala-Camin, L. A. \& A. R. G. Tomás. 1990. A pesca de atuns com espinhel no Atlântico sudoeste por barcos japoneses e brasileiros (1959 - 1979). Bol. Inst. Pesca. 17: 61 75. 